\title{
Trends in emergency department visits in Lubbock from 2011-2017
}

\author{
Sarah Jaroudi BS, Shengping Yang PhD, Gilbert Berdine MD
}

\begin{abstract}
To determine trends in daily emergency department (ED) visits, a preliminary retrospective study was done to analyze the relationship of long-term trends, day of week, and month of year to ED volume at University Medical Center in Lubbock, TX. Local data were collected from January 1, 2011, through December 31, 2017. An increase in ED visits from 2011 to 2014 was followed by a decrease in ED visits from 2014 to 2017. The best fit third order polynomial was " $y=194.9+0.3 x+0.00045 x^{2}-0.000000006 x^{3}$ " with $y=$ number of $E D$ visits and $x=$ cumulative day. The busiest day of the week was Monday with an average of 235.6 visits per day. Throughout the week, ED visits decreased to a minimum value of 201.9 visits per day on Saturday. The differences between each day of the week were significant $(p<0.001)$. Seasonal trends were present with peaks during February and September. The differences among months were significant $(p<0.001)$. The total variance of the ED visit data was decreased after adjusting for the long-term trend, day of week, and month of year. These adjustments remove noises not relevant to the study goal and are necessary for further studies testing hypotheses about factors affecting ED visits that may not be uniformly distributed over time.
\end{abstract}

Keywords: emergency department use, health care use, trends, health care demand, day of week, seasonal trends

\section{INTRODUCTION}

Emergency department (ED) visits are an important component of the health care system and serve as "safety nets" in many communities. The American Hospital Association analyzed ED trends from 1995 to 2016 and found a $51 \%$ increase in ED visits and a $12 \%$ decrease in the number of EDs within the United States. ${ }^{1}$ Similar findings have been reported in local regions such as California. ${ }^{2}$ Drivers of these trends include population growth and government health care policy. Characteristics in relation to ER trends that have been explored include age, gender, and

Corresponding author: Gilbert Berdine Contact Information: Gilbert.berdine@ttuhsc.edu DOI: $10.12746 /$ swrccc.v7i27.513 diagnosis. ${ }^{3}$ One study assessed ED utilization and found a decrease in ED visits with holidays, extreme cold temperature, and precipitation. ${ }^{4}$ Emergency department activity was higher in the winter and lower during the fall. When looking at days of the week, most visits were on Monday which was attributed to outpatient facilities being closed over the weekend. Emergency department visits also mirror changes in health care policy as there has been an upward shift in visits seen in the uninsured and Medicaid insured patients. ${ }^{5}$

With the soaring demand for and dwindling availability of EDs, it is helpful to review patterns to assist in meeting health care needs. Overcrowding is now a problem across the United States and will continue to persist as the population ages with patients presenting with increasingly complex medical conditions to the hospital. ${ }^{6}$ Our purpose was to analyze long-term trends of the University Medical Center ED use in 
Lubbock, Texas, from January 1, 2011, to December 31,2017 . We also examined the effects of the month of year and the day of week. The analysis would provide preliminary data to test hypotheses about the effect of other factors on ED use. We found significant long-term trends as well as effects of month of year and day of week. These trends represent necessary corrections that need to be made for studying factors that might be used for predicting ED visit load, such as inclement weather events.

\section{Methods}

A count of total ED visits for each day was made by computerized analysis of the electronic medical record (EMR) at University Medical Center (UMC) in Lubbock, Texas. Emergency department visits were tabulated for all dates starting from January 1, 2011, through December 31, 2017. To investigate the relationship between ED visits and dates, attempts were made to evaluate potential factors that might have a relationship with the ED visits, including long-term overall trend, day of the week, and month of year. Polynomial regression was first used to remove the long-term trend in ED visits. Then residues from the polynomial regression were fit by day of the week. Next, a second regression was fit to adjust for the month of the year effect.

\section{RESULTS}

Figure 1 shows the raw data. The $x$ axis is the number of days after January 1, 2011. The y axis is the total number of ED visits for all reasons on each date. One can see an increasing trend in ED visits for dates less than about July 1,2014 . Then there is a decreasing trend in ED visits starting from about July 1,2014 to the end of the time period at December 31, 2017. The overall trend line was $y=194.9+0.3 x+$ $0.00045 x^{2}-0.000000006 x^{3}$, where $y$ is the number of ED visits, $x$ is cumulative day.

Figure 2 shows the raw data adjusted for the longterm trends.

Table 1 shows the effect of day of the week on ED visits. Monday was the busiest day of the week

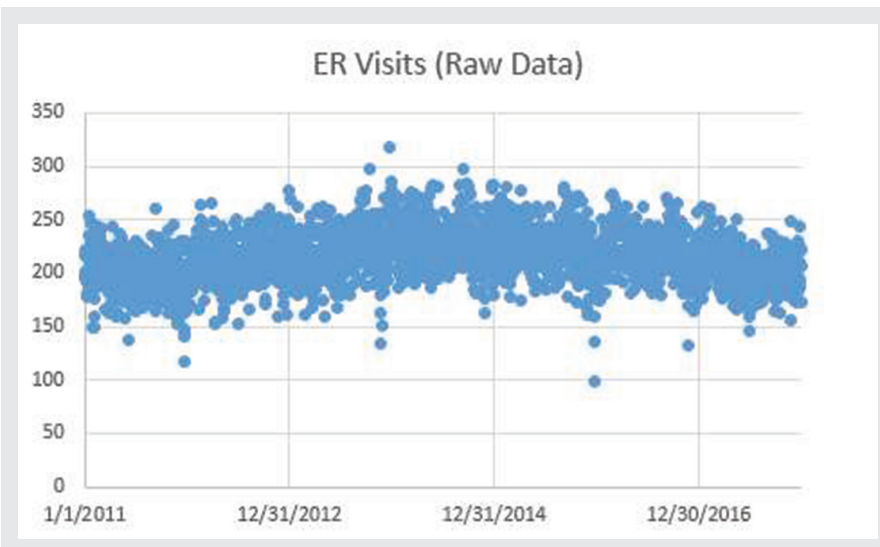

Figure 1.

with an average of 235.6 visits per day. Emergency department visits decreased on subsequent days to a minimum value of 201.9 visits per day on Saturday. Sunday had more visits than Saturday, but fewer visits than all other days. The differences among each day of the week were significant $(p<0.001)$.

Table 2 shows the effect of month of the year on ED visits. Figure 3 shows the data in Table 2 in graphical form. One can see seasonal trends with peaks during February and September. The differences among months were significant $(p<0.001)$.

Figure 4 shows data after corrections for the longterm trend lines, the day of the week, and the month of the year.

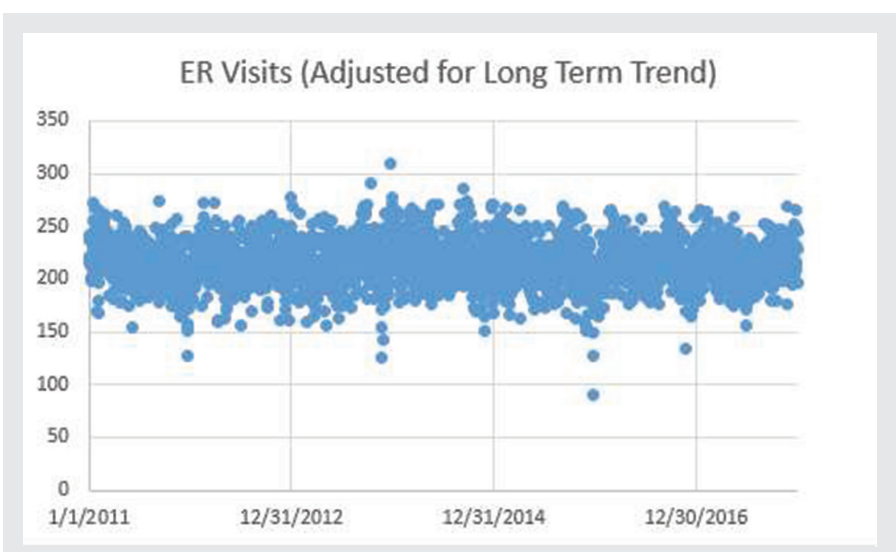

Figure 2. 
Table 1.

\begin{tabular}{|l|c|c|}
\hline \multirow{2}{*}{} & \multicolumn{2}{|c|}{ Total Daily Admits } \\
\cline { 2 - 3 } & Mean & Standard Deviation \\
\hline Monday & 235.6 & 22.8 \\
\hline Tuesday & 221.9 & 22.5 \\
\hline Wednesday & 217.3 & 21.0 \\
\hline Thursday & 211.9 & 23.7 \\
\hline Friday & 211.2 & 20.0 \\
\hline Saturday & 201.9 & 19.0 \\
\hline Sunday & 208.8 & 21.9 \\
\hline
\end{tabular}

Emergency department visits have considerable variance over time. To study any other determinants of ED visits that are not uniformly distributed over time, it is advisable to remove changes in number of visits associated with long-term trend, day of the week and month. Regression analysis shows that the total variance explained by long-term trend, day

Table 2.

\begin{tabular}{|l|c|c|}
\hline \multirow{2}{*}{ Month of year } & \multicolumn{2}{|c|}{ Total Daily Admits } \\
\cline { 2 - 3 } & Mean & Standard Deviation \\
\hline January & 217.6 & 22.7 \\
\hline February & 222.2 & 22.7 \\
\hline March & 219.1 & 22.0 \\
\hline April & 217.4 & 23.4 \\
\hline May & 212.0 & 23.4 \\
\hline June & 209.0 & 20.5 \\
\hline July & 211.3 & 19.3 \\
\hline August & 214.5 & 19.4 \\
\hline September & 225.9 & 25.8 \\
\hline October & 216.5 & 23.4 \\
\hline November & 210.0 & 24.7 \\
\hline December & 211.1 & 30.7 \\
\hline
\end{tabular}

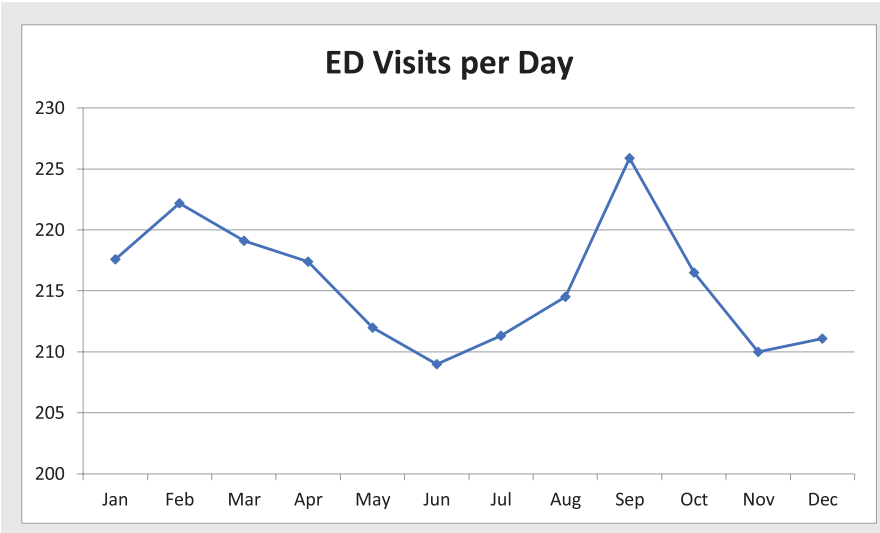

Figure 3.

of the week, and month were 265562, 258781 and 53657 , respectively ( $p$ values all $<0.001$ ). Note that these variances account for $18.3 \%, 17.8 \%$ and $3.7 \%$ of the total variance, respectively.

\section{Discussion}

Annual long-term trends of number of ED visits in the US have gradually increased since $1995 .{ }^{1}$ We found a significant long-term trend over time consisting of an increase in ED visits in Lubbock from 2011 to 2014 followed by a decrease in ED visits from 2014 to 2017. The increase is consistent with previous studies on ED visits and is likely attributable to population growth. A 9.4\% increase in the population of Lubbock,

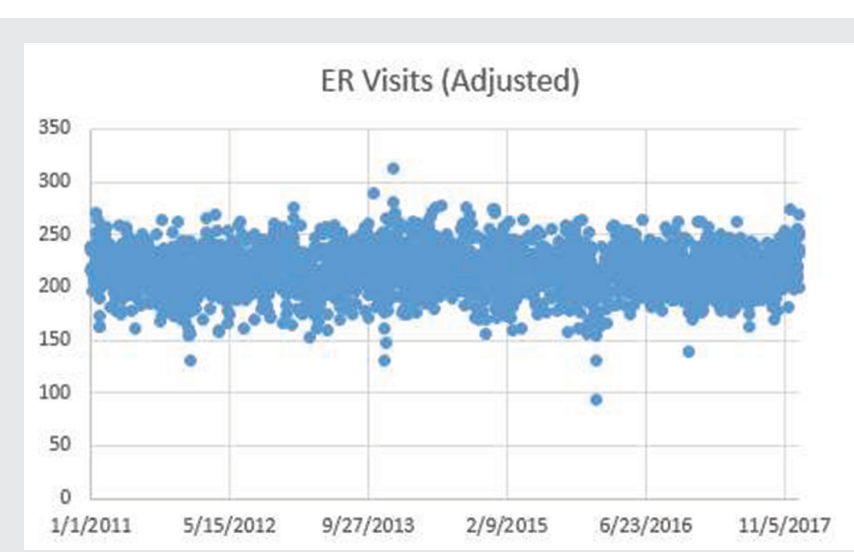

Figure 4. 
Texas, from 2010 to 2017 was estimated based on Census Bureau data. ${ }^{7}$ A California study that also showed a long-term increase in number of ED visits found that their increase in demand mirrored the public's concerns regarding ED capacity. ${ }^{2}$ The decrease we observed from 2014 to 2017 is likely due to emergence of competition in the Lubbock ED market with an increase in the number of choices of where to seek care including urgent care centers and telemedicine. ${ }^{8}$ Total ED visits in a geographic market will depend on population and the public's perception of the utility of the ED vs. other venues for health care. The dependence on population is straightforward. ED visits would increase if the public had incentives to receive care in the ED vs. outpatient offices, urgent care clinics, or other alternative providers of acute care. Third party payment for alternative venues of care can have a large role in the public's perception of the ED. For an individual ED, the other determinant of long term trend in ED use will be market share. Many factors influence market share, and this issue is beyond the scope of this study.

Numerous studies have looked at the cyclical variations in relation to day of the week, month of the year, and long-term trends. ${ }^{9,10,11}$ We found a significant effect of the day of the week on ED visits, with Monday having the highest number of visits. Emergency department visits also decreased through the remainder of the week. This is consistent with prior analyses of ED visits and is comparable to the long-term trends., ${ }^{9,11}$ One study that compared trends across three hospital EDs found that the impact of holidays and weekly patterns were variable and found an increase in patient volume the Friday after a holiday at one of their centers. ${ }^{9}$

When observing the months of the year, we found a significant effect with relation to ED visits with peaks in February and September. The effect was much smaller than either the long-term trends or the effect of the day of the week. This is in contrast to a study done in Singapore with higher patient volumes from May to July that they attributed to region-specific diseases such as dengue. ${ }^{12}$ The medical literature has been variable in results regarding the relation of time of year to ED visits. Some have shown a decrease in ED visits in colder months although one study looking at the effect of weather found no correlation to ED visits. ${ }^{13}$

Prediction formulas taking calendar variables into account have been successful in improving patient satisfaction and efficiency in staffing. ${ }^{10}$ Data analyses can be advantageous for EDs in terms of micro and macro level planning. Forecasting models for ED visits have shown stronger accuracy for short-term compared to longer-term predictions. ${ }^{11}$ Comparison of various forecasting methods have supported the impact of calendar variables on demand for ED services. ${ }^{9}$

Our study had a few limitations. First, our study was limited to a single center. The use of data of other EDs in Lubbock would allow us to compare our results. Second is the lack of data of average daily temperature. Having this information would allow for additional observation of any significant trends. Third, we did not include federal holidays as independent variables.

Much of the total variance in ED visits over time was explained by long-term trends, day of the week, and month of the year. Considerable residual variance (sum of squares) was present after adjusting for the long-term trend, day of week, and month of year. The source of this residual variance is open for further studies. Our findings can be useful for the creation of forecasting models for accuracy in predictions of ED visits in Lubbock. The adjustments made in this study should be done prior to any further analyses of causes of ED visits if variables of interest are not uniform over time.

Article citation: Sarah Jaroudi S, Yang S, Berdine G. Trends in emergency department visits in Lubbock from 2011-2017. The Southwest Respiratory and Critical Care Chronicles 2019;7(27):50-54

From: The Departments of Internal Medicine (SJ, GB) and Pathology (SY) at Texas Tech University Health Sciences Center in Lubbock, Texas

Submitted: $11 / 4 / 2018$

Accepted: 12/23/2018

Reviewer: Mike Ragain MD

Conflicts of interest: none

This work is licensed under a Creative Commons Attribution-ShareAlike 4.0 International License. 


\section{REFERENCES}

1. TrendWatch Chartbook 2018 - Chapter 3: Utilization and Volume AHA. Available from: https://www.aha.org/guidesreports/2018-05-23-trendwatch-chartbook-2018-chapter-3utilization-and-volume.

2. Lambe S, Washington DL, Fink A, et al. Trends in the use and capacity of California's emergency departments, 19901999. Ann Emerg Med 2002;39(4):389-96.

3. Skinner HG, Blanchard J, Elixhauser A. Trends in emergency department visits, 2006-2011: Statistical Brief\#179. Agency for Healthcare Research and Quality (US); 2006. Available from: http://www.ncbi.nlm.nih.gov/pubmed/25473724.

4. Faryar KA. The effects of weekday, season, federal holidays, and severe weather conditions on emergency department volume in Montgomery County, Ohio. 2013. Available from: http://corescholar.libraries.wright.edu/mph.

5. Tang N, Stein J, Hsia RY, et al. Trends and characteristics of US emergency department visits, 1997-2007. JAMA 2010; 304(6):664-70.

6. Di Somma S, Paladino L, Vaughan L,et al. Overcrowding in emergency department: an international issue. Intern Emerg Med 2015;10(2):171-5.
7. U.S. Census Bureau QuickFacts: Lubbock County, Texas. United States Census Bureau. 2017; Available from: https:// www.census.gov/quickfacts/fact/table/lubbockcountytexas/ PST045217

8. Poon SJ, Schuur JD, Mehrotra A. Trends in visits to acute care venues for treatment of low-acuity conditions in the United States From 2008 to 2015. JAMA Intern Med 2018;178(10): 1342.

9. Jones SS, Thomas A, Evans RS, et al. Forecasting daily patient volumes in the emergency department. Acad Emerg Med 2008;15(2):159-70.

10. Batal H, Tench J, McMillan S, et al. Predicting patient visits to an urgent care clinic using calendar variables. Acad Emerg Med 2001;8(1):48-53.

11. Marcilio I, Hajat S, Gouveia N. Forecasting daily emergency department visits using calendar variables and ambient temperature readings. Acad Emerg Med 2013;20(8):769-77.

12. Sun $Y$, Heng BH, Seow YT, et al. Forecasting daily attendances at an emergency department to aid resource planning. BMC Emerg Med 2009;9(1):1.

13. Attia MW, Edward R. Effect of weather on the number and the nature of visits to a pediatric ED. Am J Emerg Med 1998;16(4):374-5. 